\title{
Analysis of RAM (Reliability, Availability, Maintainability) Production of Electric Voltage from 48 V PV (Photovoltaic) at Pantai Baru Pandansimo, Indonesia
}

\author{
Fizanti Causia Aguisti", Ali Musyafa', and Muhammad Khamim Asy'ari \\ Department of Engineering Physics, Institut Teknologi Sepuluh Nopember, Indonesia. \\ Jl. Teknik Kimia, Sukolio, Surabaya 60111, Indonesia
}

\begin{abstract}
The production on electrical voltage from photovoltaic has fluctuating performance, so it needs to be maintained with optimum control and operational system. Reliability in operation maintenance needs to be maintained, so that the production of electric voltage can be maintained. The analysis is done by calculating the reliability based on the failure rate $(\lambda)$ that obtained from the value of out of scope contained on the control chart. The variation given is in the form of a failure rate $(\lambda)$ based on the standard deviation limit. The reliability and availability values are obtained based on the failure rate $(\lambda)$ while the maintainability values are obtained from the value of repair $(r)$ based on the results of an interview. The failure rate $(\lambda)$ obtained has a constant value of 0.0274 . The reliability value of the photovoltaic system has decreased to 0.55 after the photovoltaic system operates for $22 \mathrm{~d}$. The photovoltaic system has a high availability of 0.998 which is constant at $t=20 \mathrm{~d}$. The photovoltaic system will achieve maintainability of 1 at $t=13 \mathrm{~d}$.
\end{abstract}

Keywords: Fluctuating performance photovoltaic, renewable energy, solar energy, Shewhart control chart

\section{Introduction}

The role of electrical energy in daily life has increased significantly. Even lately the case that occurred in the capital city of Jakarta and surrounding areas, namely mass blackouts or blackout, has been reported in various media. The mass outage was due to an interruption of the transmission of the $500 \mathrm{kV}$ Extra High Voltage Air Line Ungaran, Pemalang, Indonesia [1]. The availability of electricity itself is the responsibility of the government in accordance with the 1945 Constitution of the Republic of Indonesia Article 33 paragraph 2, which states that the business of providing electricity is controlled by the State and is used for the prosperity of the people whose implementation is carried out by the central government and regional governments [2]. The government makes policies in the energy sector, namely the National Energy Policy as set out in Government Regulation Number 79

*Corresponding author: fizantia@gmail.com 
of 2014 in ensuring the availability of electricity. The government began to implement new renewable energy to increase national electricity supply to realize the availability of electricity throughout the country [2].

Utilization of EBT (Renewable Energy) generally currently only reaches $5 \%$ of the national mix. The use of EBT has its own purpose as an alternative to the use of fossil energy, where the effect is to reduce greenhouse gas emissions, which in the future is also expected to reduce the cost of energy production used daily. The current source of EBT itself can only be enjoyed with technology that is still in the development stage, so the investment costs needed are quite high, but in the future technology devel opment is expected to reduce the cost to be relatively low. Some types of EBT that are starting to be used frequently and are still in the development stage include the use of wind, water, and sunlight as energy sources [3]. Natural conditions in Indonesia have unstable wind and water speeds, the use of sunlight can be used as a solution to the existing problems. Utilization of sunlight as an energy source is also often used for places that are difficult to reach. Sunlight is also used as an energy source in solar power generation systems or as we often know photovoltaics which can be used as an alternative in increasing the supply of electrical energy.

PLTH - [Pembangkit Listrik Tenaga Hibrida (Hybrid Power Plant)] Pantai Baru Pandansimo, Indonesia, built in 2010, is a realization of the Regional Innovation System (SIDa) initiated by the Ministry of Research and Technology, various government actors, business actors, and the wider community involved in realizing environmentally friendly PLTH. At present, the PLTH is managed by the Energy and Mineral Resources Licensing Control Agency (BP3 ESDM) in the Bantul and Kulon Progo regions with a capacity of each photovoltaic panel of $110 \mathrm{Wp}$ and $220 \mathrm{Wp}$ [4]. Quality, continuity, and availability of services are vital factors in the process of electricity supply distributing. There are problems in the photovoltaic voltage production process such as reliability, availability, and maintainability [5] which can affect the process of electricity supply distributing. Therefore, it is necessary to analyze the reliability, availability, and maintainability of the photovoltaic system. The method used to analyze reliability, availability, and maintainability is a control chart. The use of the Shewhart control chart has several advantages [6], including showing the variation caused by damage to the equipment that causes the influence of worse conditions. These causes can usually be identified and can then be corrected by repairing the machine or changing the material.

\section{PLTH (Hybrid Power Plant)}

PLTH Pantai Baru Pandansimo develops two Hybrid Energy namely wind turbines and photovoltaics. PLTH Pantai Baru Pandansimo is located on the southern coast of Yogyakarta, the location is a large open area, so the sun can shine on photovoltaics throughout the day and windmills can spin with an average wind speed of $4 \mathrm{~m} \mathrm{~s}^{-1}$ [4]. This condition makes Pantai Baru Pandansimo selected as the location for the development of Hybrid Energy.

Table 1. Electricity energy group

\begin{tabular}{|c|c|c|c|c|}
\hline \multicolumn{3}{|c|}{ Type of Group } & Number of Units & Total Power \\
\hline East Group & $48 \mathrm{~V}$ System & $2 \mathrm{kWp} 48 \mathrm{~V}^{-1}$ & 20 Unit @100Wp 24V $\mathrm{V}^{-1}$ & $2 \mathrm{kWp}$ \\
\hline KKP Group & $48 \mathrm{~V}$ System & $10.5 \mathrm{kWp} 48 \mathrm{~V}^{-1}$ & 48 Unit @220Wp24V & $10.5 \mathrm{kWp}$ \\
\hline
\end{tabular}




\section{Control chart method for RAM (Reliability, Availability, Maintainability) analysis}

\subsection{Control Chart}

Control chart is a chart that gives an overview of the behavior of a process. A process that is quite stable, but goes beyond the expected limits, needs to be improved to find the root cause in order to obtain fundamental improvement results. The control chart consists of [7] points representing a statistical value (average, range, proportion) of a sample characteristic taken from a process at different times, the average of the statistical values calculated from the whole sample, the center drawn line is appropriately raised by the average statistical value, the standard deviation of the statistical value is also calculated from the whole sample, and the upper and lower control limits that indicate the boundary at which a process can be said to be deviating generally with a magnitude of three times the standard deviation of the midline [8]. An example of a control chart can be seen in Figure 1.

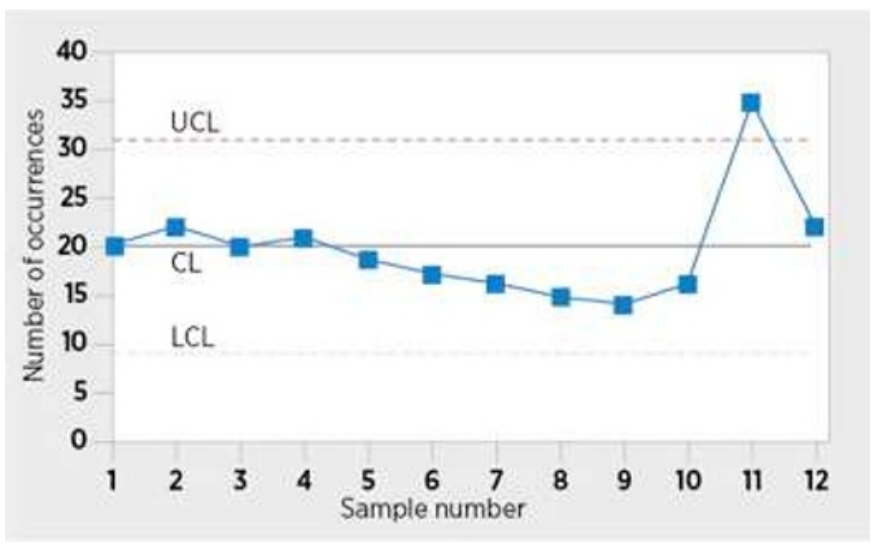

Fig. 1. Control chart

There are several stages in making a control chart, namely the calculation of the average, the calculation of standard deviations, and the calculation of the upper and lower limits. The average equation is shown in Equation (1).

$$
\bar{x}=\frac{\sum_{i=1}^{n} x_{i}}{n}
$$

$\bar{x}$ is average, $x_{i}$ is the $i$-th voltage production data, and $\mathrm{n}$ is the amount of data. Equation standard deviation is shown in Equation (2).

$$
\sigma=\sqrt{\frac{\sum_{i=1}^{n}\left(\bar{x}-x_{i}\right)^{2}}{n-1}}
$$


$\sigma$ is standard deviation. The lower bound and upper limit equation is shown in Equation (3) to Equation (4).

$$
\begin{aligned}
& L C L=\bar{x}-Z \sigma \\
& U C L=\bar{x}-Z \sigma
\end{aligned}
$$

$Z$ is a constant that has values 1,2 , and 3 . The value of $Z$ corresponds to the level of confidence. $Z$ of 1 indicates a confidence level of $68 \%, Z$ of 2 indicates a confidence level of $95 \%$, and $Z$ of 3 indicates a confidence level of $99 \%$ [9].

\subsection{Reliability}

Reliability is the possibility of a system to operate or carry out its functions. Reliability evaluation can help in estimating the chances of a system to carry out its functions within a certain period and under certain conditions. The value of the reliability function is a probability value, then the value of the reliability function $(R)$ is $0 \leq \mathrm{R} \geq 1$. The reliability function is denoted as $R(t)$ of the system if used for $t$ units of time. The probability of the system cam function properly during usage $[0, t]$. Calculation of the reliability value use an exponential distribution and is shown in Equation (5)[10].

$$
R(t)=e^{-\lambda t}
$$

$R$ is the reliability value from $0-1, \lambda$ is failure rate, $t$ is time. The failure rate value is obtained through Equation (6).

$$
\lambda=\frac{p}{n}
$$

$p$ is the amount of data that is out of scope and $n$ is the amount of data.

Preventive maintenance is used to prevent failure before total damage occurs. Predictive maintenance is categorized into scheduled on condition task activity, that is activity in checking potential failures so that failure can be prevented to avoid the consequences of malfunction. The calculation of preventive maintenance value uses an exponential distribution and is shown in Equation (7).

$$
R m(t)=R(T)^{n} R(T-n T)=R(t)
$$

$R m(t)$ is the reliability of the system after cumulative preventive maintenance activities are implemented, $R(T)^{n}$ is the probability of resilience to the $n$-th preventive maintenance, and $R(t-n T)$ is preventive maintenance, the probability of resilience during the $t-n T$ period is predetermined before the initial conditions. 


\subsection{Availability}

Availability is the possibility of a system to carry out its functions (with various aspects of reliability, mixture, support of care). Availability that changes with time. The calculation of the availability value uses an exponential distribution and is shown in Equation (8).

$$
A(t)=\frac{r}{\lambda+r}+\frac{\lambda}{\lambda+r} e^{-(\lambda+r) t}
$$

$A$ is the availability of a system to carry out its function, $\mathrm{r}$ is the rate of repair, $\lambda$ is the failure rate, and $t$ is the time.

\subsection{Maintainability}

Maintainability is the ability of a damaged system to be repaired at its original reliability within a certain time, in accordance with predetermined procedures. Maintainability is very closely related to MTTR. Maintainability has a different formula in each distribution depending on the data. The maintainability value uses an exponential distribution and is shown in Equation (9) [11].

$$
M(t)=1-e^{-r t}
$$

$M$ is the ability of a damaged system to be repaired and $r$ is the rate of repair. Rate of repair value is obtained through Equation (10).

$$
r=\frac{1}{M T T R}
$$

MTTR adalah mean time to repair.

\section{Results and discussions}

\subsection{Control chart}

The data used is the production of electrical voltage from $48 \mathrm{~V}$ photovoltaics. Data was taken from July 1, 2018 to June 30, 2019, with the calculated data $365 \mathrm{~d}$. The control chart calculation results are shown in Figure 2.

The results obtained in Figure 2. shows an average value of 53.2, a UCL1 value of 62.21, an $L C L 1$ value of 44.16, for $U C L 1$ and $L C L 1$ having a confidence level of $68 \%$, a $U C L 2$ value of equal to 71.24, and the $L C L 2$ value is 35.13, for $U C L 2$ and $L C L 2$ it has a $95 \%$ confidence level. From the values obtained, there are 10 data that are out of scope from the expected limit. From the out of scope, the failure rate value obtained from the photovoltaic system is 0.0274 . The failure rate results obtained indicate that the failure rate has a constant value. It is assumed that the photovoltaic system is in useful life with an exponential type of distribution. 


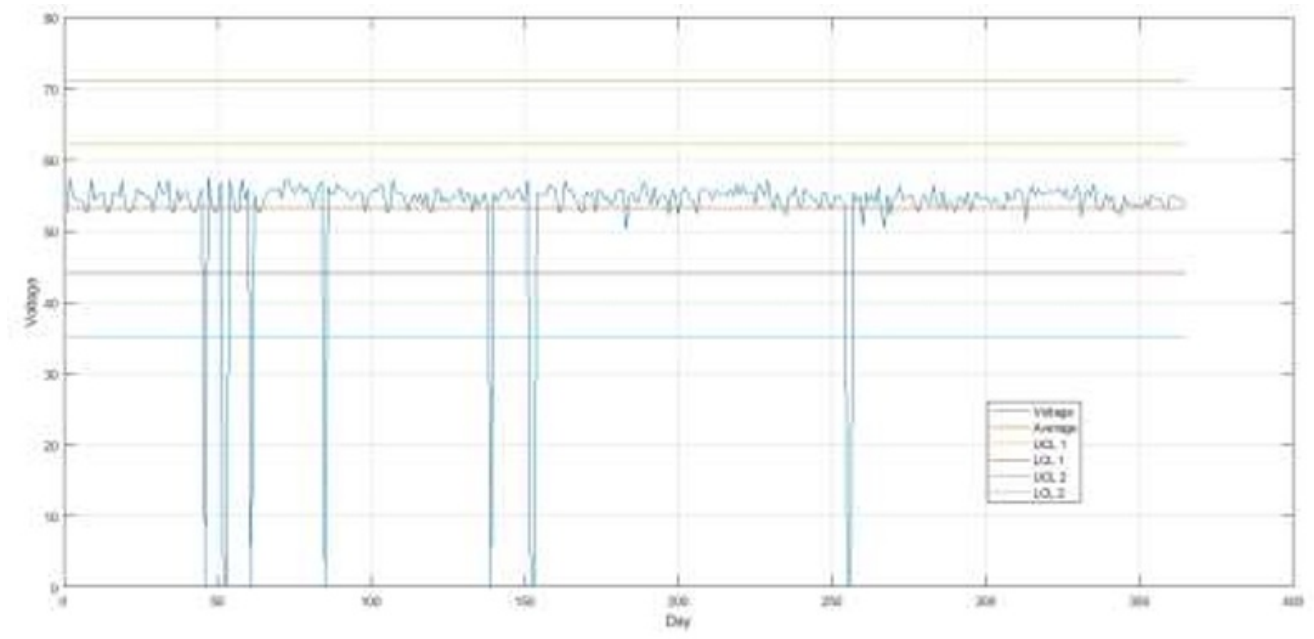

Fig. 2. $48 \mathrm{~V}$ photovoltaic system control chart

\subsection{Reliability analysis}

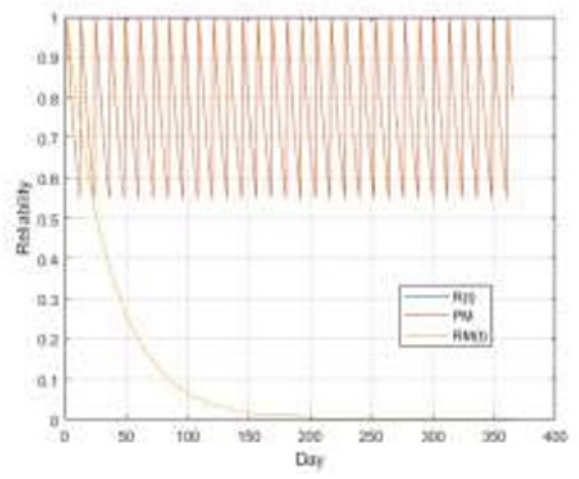

Fig. 3. Reliability chart

The reliability calculation uses Equation (5). The reliability calculation results are shown in Figure 3. The reliability value of 0.55 occurs when the photovoltaic system has been working for $22 \mathrm{~d}$. This proves that the reliability of the photovoltaic system is quite poor, so that preventive maintenance is carried out. Preventive maintenance is implemented on photovoltaic systems with a standard reliability value of 0.55 . The cumulative implementation results obtained are shown in Figure 3 with the description of $\operatorname{Rm}(t)$. Figure 3 shows that there is no change between the initial reliability and the implementation carried out, namely preventive maintenance. There are several factors that cause the reliability of a photovoltaic system that cannot work reliably. Some of these factors include natural conditions that are difficult to predict, human errors, component defects that are not detected, and others. 


\subsection{Availability analysis}

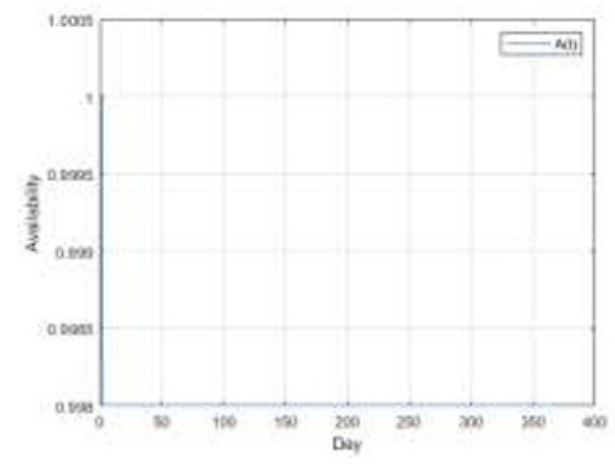

Fig. 4. Availability chart

The availability calculation uses Equation (8). The results of the availability calculation are shown in Figure 4 is showing that the photovoltaic system has a high availability. The level of availability of a photovoltaic system is constant at $t=20 \mathrm{~d}$ with a value of 0.99 .

\subsection{Maintainability analysis}

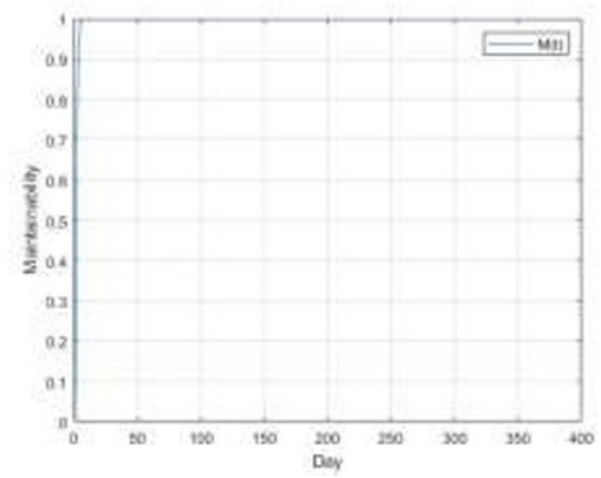

Fig. 5. Maintainability chart

Maintainability calculations are obtained using MTTR values. The MTTR value is obtained from the average how long the repairs on the $48 \mathrm{~V}$ photovoltaic system are carried out until the system can work properly. MTTR value obtained is $1 \mathrm{~d}$. Figure 6 shows that the photovoltaic system will achieve maintainability of 1 at $\mathrm{t}=13 \mathrm{~d}$.

\section{Conclusion}

A reliability value of 0.55 occurs when the photovoltaic system has been working for $22 \mathrm{~d}$. This proves that the reliability of the photovoltaic system is quite poor, so that preventive maintenance is carried out. If preventive maintenance is implemented in voltage production with a reliability standard of 0.55 , it was shown that the implementation of preventive maintenance result will be the same as the value of reliability itself. Some steps that can be taken to improve the reliability of a photovoltaic system are by periodically checking important components of the system, periodic maintenance before damage occurs, and if 
there are tall trees, keep them as far as possible, so that sunlight can fully illuminate photovoltaics. The availability value at time $\mathrm{t}=20 \mathrm{~d}$ is 0.998 and the value of maintainability is 1 at time $\mathrm{t}=13 \mathrm{~d}$.

\section{References}

1. H.F.S. Utomo, Jakarta Blackout, [Online from] https://www.liputan6.com/global/read/4029398/jakarta-blackout-mati-lampu-di-ibukota-disorot-media-asing (2019). [Accessed 20 August 2019]. [in Bahasa Indonesia].

2. Kepmen ESDM. 2019. Keputusan Menteri ESDM tentang Ketenaga Listrikan Nasional. [in Bahasa Indonesia] https://jdih.esdm.go.id/storage/document/Kepmen-esdm-143Thn\%202019\%20RUKN\%202019.pdf

3. I. Kholiq, IPTEK, 19,2:75-91(2015). [in Bahasa Indonesia] https://ejurnal.itats.ac.id/iptek/article/download/12/12

4. T. Suhartanto, JNTETI, 3,1:76-82(2014). http://ejnteti.jteti.ugm.ac.id/index.php/JNTETI/article/vimmnew/48/68

5. A.M. Al-Shaalan, J. King Saud Univ. Eng. Sci., 24,1:11-18(2012). https://www.sciencedirect.com/science/article/pii/S1018363911000560

6. J.C. Benneyan, nt. J. Six Sigma Competitive Advant., 4,4:209-239(2008). https://www.researchgate.net/publication/228941929_The_design_selection_and_perfo rmance_of_statistical_control_charts_for_healthcare_process_improvement

7. J. Berk, S. Berk, Quality Management for The Technology Sector, 2000,10:88-105 (2007). https://www.sciencedirect.com/science/article/pii/B9780750673167500103?via\%3Dih $\underline{\mathrm{ub}}$

8. N.G. Sengoz, Control charts to enhance quality In: Quality Management Systems - a Selective Presentation of Case-studies Showcasing Its Evolution, L.D. Kounis (Ed), UK: IntechOpen (2018). https://www.intechopen.com/books/quality-management-systems-a-selectivepresentation-of-case-studies-showcasing-its-evolution/control-charts-to-enhancequality

9. A. Hazra, J. Thorac. Dis., 9,10:4125-4130(2017). https://www.ncbi.nlm.nih.gov/pmc/articles/PMC5723800/

10. A. Sayed, M. El-Shimy, M. El-Metwally, M. Elshahed, Energies, 12,7:1-18(2019). https://www.researchgate.net/publication/332080332 Reliability_Availability and Ma intainability_Analysis_for_Grid-Connected_Solar_Photovoltaic_Systems

11. B.S. Dhillon, Maintainability, Maintenance, and Reliability for Engineers, USA: CRC Press (2006). p. 87-95. https://doi.org/10.1201/9781420006780 